\title{
Mycetomorpha, a new Rhizocephalan
}

(with a note on the sexual condition of Sylon).

By

\section{F. A. Potts,}

Fellow of Trinity Hall, Cambridge (England).

(From the Zoological Laboratory of the University of Cambridge.)

\section{With Plates $15-16$ and 12 Figures in the text.}

\section{Contents.}

Introduction.

The Host.

General Account of the Anatomy.

The Rootsystem.

The Mantle Duct.

The Mantle Cavity and its relation to the Visceral Mass.

The Structure of the Visceral Mass.

The Developing Eggs.

The Glands of the Visceral Mass.

The Larvae.

Relationships of Mycetomorpha.

Diagnosis of Mycetomorpha vancouverensis.

A note on the sexual condition in Sylon.

\section{Introduction.}

The animal which is described here under the name of Mycetomorpha vancouverensis $n . g$. n. sp. was dredged outside the harbour 
of Nanaimo, Vancouver Island in August, 1911. A single shrimp of the species Crangon communis RAтнв. was noticed, to the ventral surface of which was attached a pale yellow fungus-like body fringed with numberless lobes and so wide as to impede the action of the abdominal appendages. Examination in the laboratory showed at once the presence of characteristic Cirripede larvae and it became quite clear that this was a new or little known Rhizocephalan. Even more curious than the external appearance was the internal structure revealed by a minute study of the animal and I hasten to record such facts of structure and biology as could be ascertained from this single specimen. It was fixed in corrosive-sublimate solution with acetic acid as soon as a cursory examination of the living animal had been made. On arrival at Cambridge careful drawings of the external appearance were made and then a complete series of sections was cut. From their study it was possible to reconstruct a great deal of the structure of the animal.

I should like to take this opportunity of acknowledging my indebtedness to the Canadian Government who maintain the Biological Station at Departure Bay, Nanaimo, British Columbia, to the members of the controlling Biological Committee who arranged that I should be allowed to take advantage of its facilities and to the Director, the Rev. G. W. Taylor, for his personal kindness to me.

\section{The Host.}

\section{Crangon communis Rathbun.}

The following notes of the distribution of this shrimp are taken from Miss Rathbun's account of the Crustacea in the Harriman Expedition Reports.

"Crangon communis Rathbun, The Fur Seals and Furseal Islands of the North Pacific Ocean 1899 Pt. 3 p. 556.

Distribution. From Bering Sea to San Diego in California (including Puget Sound and Straits of Fuca), 20-309 fathoms, taken at 142 stations by the Albatross often in large numbers. Less abundant at southern localities. Off southeastern coast of Kamchatka, 96-100 fathoms, at two Albatross stations."

My own specimen was taken between Newcastle Island and the Five Fingers Rocks, close to the mouth of Departure Bay, Vancouver Island, at a depth of about 15 fathom on a rocky bottom. Examples of this grey shrimp were not infrequent in the dredge, but not more than 20-30 passed under my observation altogether. 
General Account of the Anatomy.

The external appearance of the parasite on the host is represented in the two excellent drawings (Pl. 15 Fig. 1 and 2) which were made for me by Mr. Edwin Wilson of Cambridge. In the first figure the parasite is seen extending under the posterior part of the thorax and the three anterior abdominal segments of the host. It was a very pale yellow in colour and measured nearly $1 \mathrm{~cm}$ in breadth and $1,8 \mathrm{cms}$ in length (about two-fifths the length of the shrimp). In the lateral view (Pl. 15 Fig. 2) the pleura and appendages of the adjacent segments of the host are removed to obtain a fair view of the parasite and some idea is given of the shortness of the peduncle and the flattening of the body where it comes into contact with the ventral surface of the host.

The external feature which distinguishes this genus at the first glance from the other Rhizocephala is the number of clubshaped lobes containing diverticula of the mantle cavity which come off from the entire circumference of the sacshaped body and give the animal an appearance not unlike that of the mushroom gland of the male cockroach. The lobes are arranged in three tiers and fiftyfive of them were counted altogether. They vary slightly in size and while anteriorly they are always simple the posterior ones have a tendency to fork and become hammershaped. At their attachment to the central body they possess a narrow neck.

The central part of the body is a rather elongated oval, flattened on the upper surface ${ }^{1}$ ), slightly convex underneath. It appears on a cursory inspection to be regular but the correct configuration is obscured by the bending over of the lobes and when these are turned back an indentation of the left border is revealed which indicates the attachment of the visceral mass. It will be convenient to refer to this feature throughout as the "bay".

Another remarkable character is the thinness of the mantle due to the slight development of the muscular layers. It is so thin as to be nearly transparent and both on capture and after fixation the countless numbers of Cypris larvae which fill the mantle cavity

1) In consequence of the great asymmetry of the animal I shall refer simply to the upper and under surfaces the former being that part which is apposed to the ventral surface of the host, and to the anterior and posterior parts of the parasite corresponding to the same parts of the host. 
could be dimly seen through it and are indicated in Plate 15. It was possible by making a slight incision in the mantle to draw off all the larvae in the mantle cavity and then to obtain some idea of the internal arrangement.

Through the under surface of the mantle (Fig. A) can be seen the curved visceral mass adhering closely to the left hand margin of the body except where it is separated from it by an opaque white structure described below as the mantle duct and serving to place the mantle cavity in communication with the exterior. The visceral mass itself was, in this individual, semitransparent in consequence of the spent condition of the ovary and marked externally with radiating ridges corresponding to internal septa. The mantle is faintly striated longitudinally owing to the presence of muscles and anteriorly to the bay contains a large number of small rounded bodies which I think there is reason for regarding as segmenting eggs. These give a characteristic appearance to the under surface as seen through a lens.

The following notes refer to the appearance of the upper surface when the animal has been carefully detached from its host (Pl. 16 Fig. 3). The short peduncle is surrounded as usual by a chitinous ring but this is not uniform in shape or thickness. The anterior edge is much thickened and drawn out into a prominent chitinous spike; the curvature of the posterior edge much less marked and the chitin thinner. A lateral view as shown in Fig. 1 clearly indicates that the peduncle is not set vertically to the surface of the host but really runs antero-posteriorly from host to the body of the parasite.

The bay in the left hand margin is not seen from the upper surface although the visceral mass and mantle duct are easily observed through the mantle. The bodies referred to above as segmenting eggs, are absent from the upper surface of the mantle.

The Root System.

The Root System (Pl. 16 Fig. 4) in this creature does not form a compact mass as in Peltogaster or a widely ramifying system affecting every organ in the body of the host like that possessed by Sacculina. But the roots are mainly to be found below the ventral nerve cord of the shrimp running longitudinally in the form of a matted strip short branches being given off laterally, some hardly projecting from beneath the nerve cord, others terminating in the 
ventral musculature of the host. They sometimes fork and end in clubshaped swellings containing a crowded mass of nuclei. Posteriorly they can be traced for about the length of a segment and a half in the host and anteriorly for a lesser distance. They are probably white in colour and in their general histological character they resemble those of Sacculina and Peltogaster. Under a thick cuticle lies an irregular epithelium and the interior is occupied by much vacuolated tissue with very small nuclei. At the junction of the roots in the neighbourhood of the peduncle a large and distinct lacuna is found and the further course of this is described below.

It now remains to trace the anatomy of the animal as revealed in sections: these were cut transversely as shown in Fig. A.

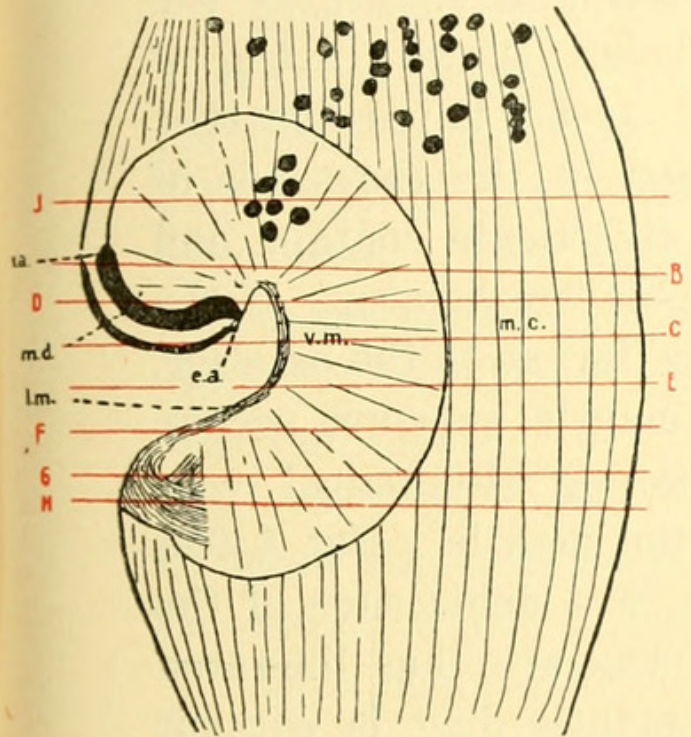

Fig. A.

Diagram of the visceral mass showing its relation to the mantle cavity. Seen from the under surface. $v . m$ visceral mass, m.c mantle cavity, m.d mantle duct, $i . a$ internal and e. $a$ external aperture of mantle duct, l. $m$ lateral mesentery.

The longitudinal shading indicates the musculature of the mantle and the black spots the developing eggs within it.

The red lines represent the vertical planes in which the figures corresponding to the lettering were cut.

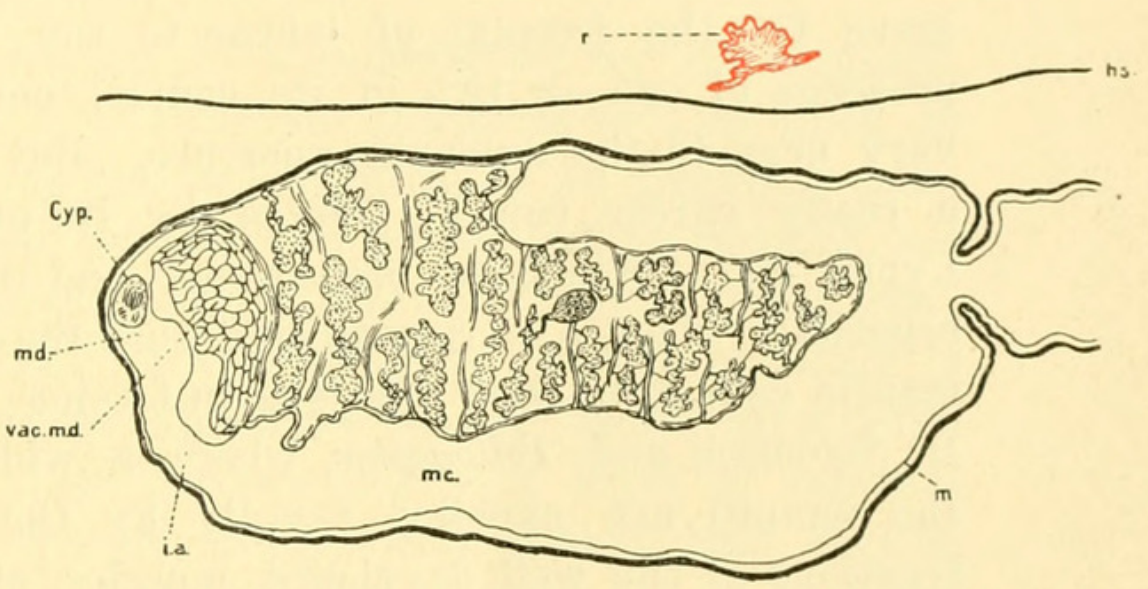

Fig. B. Transverse Section showing the internal aperture of the mantle duct.

$r$ root system, hs chitinous exoskeleton of host, $m$ mantle, vac. m. d vacuolated tissue of mantle duct, Cyp Cypris larva. Other abbreviations as in Fig. A.

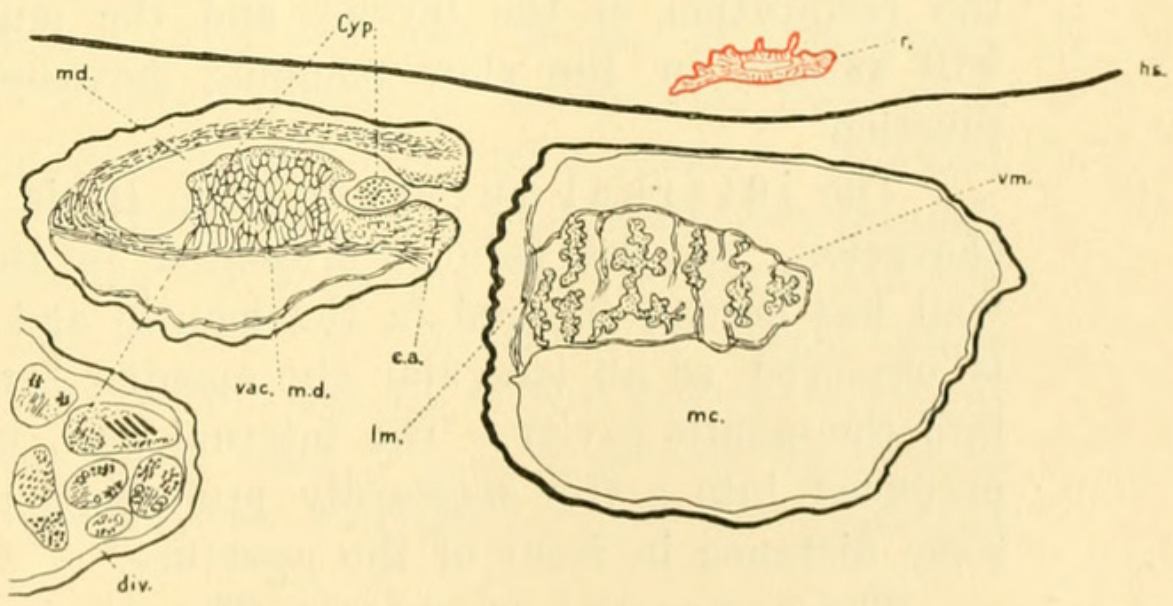

Fig. C. Transverse section showing the external aperture of the mantle duct. div diverticulum of mantle cavity filled with Cypris larvae. Other abbreviations as in Fig. A and B. 
The Mantle Duct.

Under this title I refer to the tubular structure running on the left side of the body between the visceral mass and the mantle. It opens into the mantle cavity anteriorly and to the exterior at the apex of the bay. In sections (Figs. B, C) it is seen that the walls of the duct are partly composed of a highly vacuolated tissue with very small nuclei, which appears to have a skeletal value $(v a c . m . d)$. But this tissue is not developed regularly but very thickly on the under and anterior surfaces of the wall. As indicated, however, in Fig. A the posterior part of the wall is much thinner and is made up of fibrous cells.

The lumen of the duct is considerably restricted. That it can serve for the passage of larvae to the exterior is shown by the presence of one or two in its course, one being shown in Fig. C very near to the external aperture. But it seems impossible that a ready egress can be offered by its means to the thousands of Cypris larvae which the brood pouch and its diverticula contain, and especially when it is remembered that the feeble musculature of the mantle cannot be very effective in forcing the larvae to the exterior. In Sacculina and Peltogaster, where a wide mantle aperture occurs, the nauplii are expelled rapidly by the strong rhythmical contractions of the well developed muscles of the mantle. But I feel inclined to suggest that in this case there is a dehiscence of the thin wall of the diverticula and that the larvae are thus liberated with promptitude at the proper time. The mantle duct is without doubt an essential organ in permitting the access of pure water for the respiration of the larvae, and the musculature of the mantle will suffice for the slow pumping movements which subserve this function.

The internal aperture (Fig. B) is of a curiously irregular character. At the point represented in this section the external wall has become merged in the mantle and the lumen of the duct is observed as an irregular slit opening towards the under surface into the mantle cavity. The internal wall, with its vacuolated cells, produced into a free forwardly projecting process which only ends some distance in front of the aperture.

The external aperture (Fig. C) is a small circular orifice opening into the angle of the bay. 
The Mantle Cavity and its relation to the

Visceral Mass.

When the small visceral mass is first seen in relation to the mantle cavity it is realised how considerable is the development of the mantle cavity compared with other Rhizocephala. The dimensions are further increased by the lateral diverticula which communicate (Fig. E) with the main cavity, and which serve the purposes of secondary brood pouches. The great development of the mantle cavity is due to the great numbers of larvae which are produced as well as to the large size of the larvae themselves. At the time of capture the entire cavity was tightly packed with the Cypris forms, but in the sections as drawn for this paper they are omitted in the central cavity.

The mantle (cf Pl. 16 Fig. 5) is remarkable for its thinness. There is externally a cuticle of moderate thickness (but as thick as the whole of the rest of the mantle) secreted by an irregular ectodermal epithelium (ect) with well marked nuclei but no definite cell boundaries. This is succeeded by a layer of muscle fibres (mu), which are mostly longitudinal in arrangement. The musculature is especially developed round the apertures of the lateral diverticula into the mantle cavity. Lastly there is a thin layer of internal ectoderm $\left(e c t^{1}\right)$ lining the mantle cavity, with a very thin cuticle. Between the internal ectoderm and the muscle layer are to be found the bodies which I regard as eggs retarded in development.

The mesenteries. The main attachment of the visceral mass to the mantle is effected by a very thin lateral mesentery, running on the curved left side of the body (cf. Fig. A, E, F, G etc.). But in front of the apex of the bay and in the neighbourhood of the mantle duct an extensive fusion of the visceral mass with the mantle has taken place both dorsally and ventrally. A small diverticulum of the mantle cavity is however found in sections through this region (Fig. D) intruding between the visceral mass and the under surface of the mantle and this increases in extent when traced forward, until in the neighbourhood of the internal aperture of the mantle duct the visceral mass is only supported by a wide dorsal concrescence with the mantle. Further forward the connection ceases altogether.

The connection of the rootsystem with the visceral mass (cf. Fig. J). The rootsystem passes through the peduncle by 


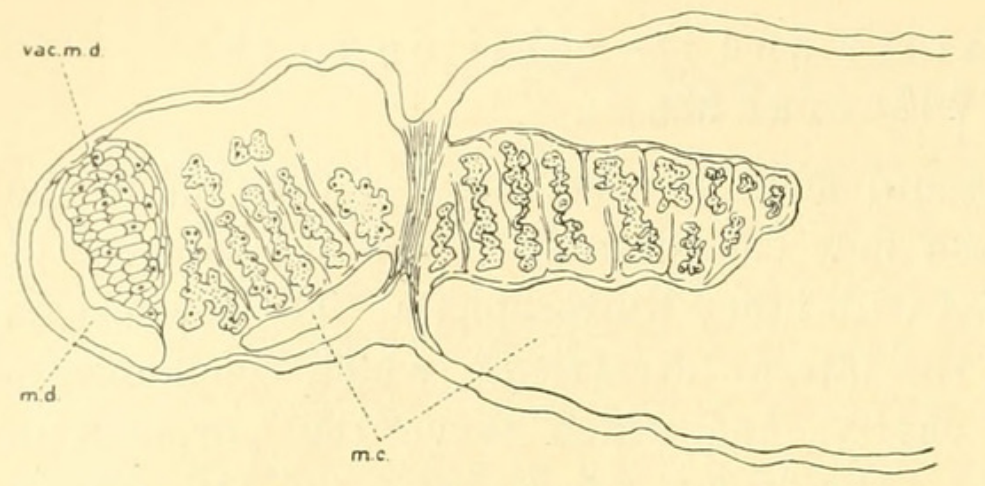

Fig. D.

Transverse section through visceral mass just in front of the bay. Abbreviations as in preceding figures.

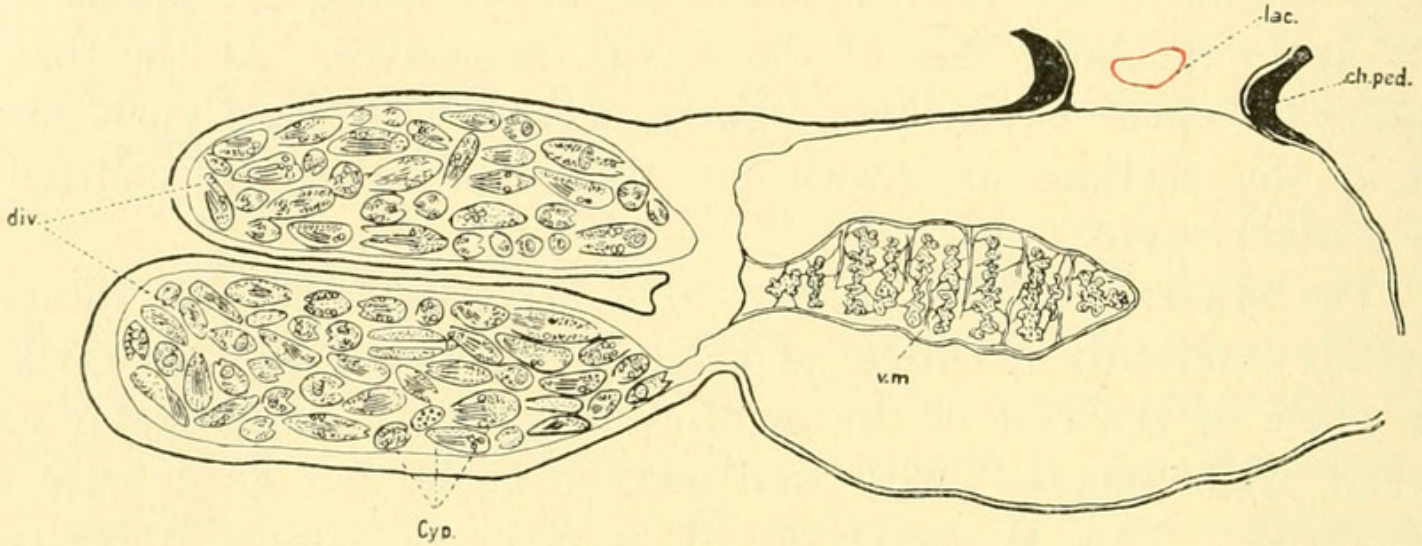

Fig. E. Transverse section through peduncle.

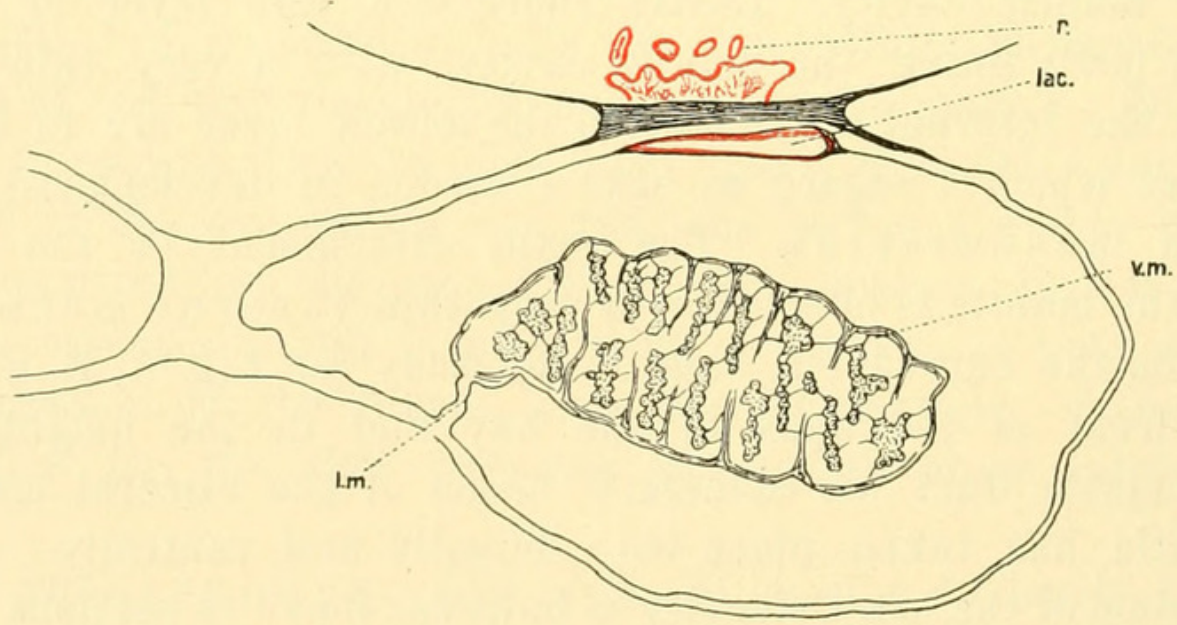

Fig. F.

a strand of tissue which contains a wide and definite lacuna (Fig. E). This does not, however, pass straight to the visceral mass but runs posteriorly for a considerable distance in the upper surface of the mantle (Fig. F) at the same time shifting slightly toward the left side. But at the point where the section drawn in Fig. G is taken there is a projection of the peduncular tissue which soon fuses with the 


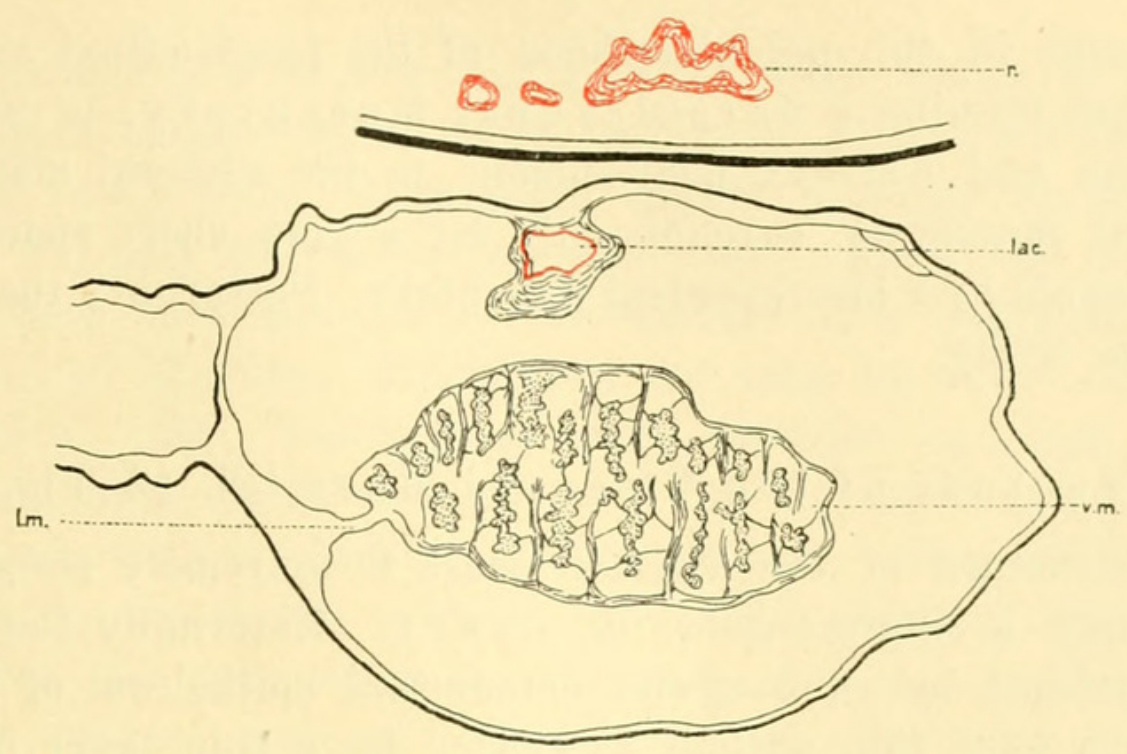

Fig. G.

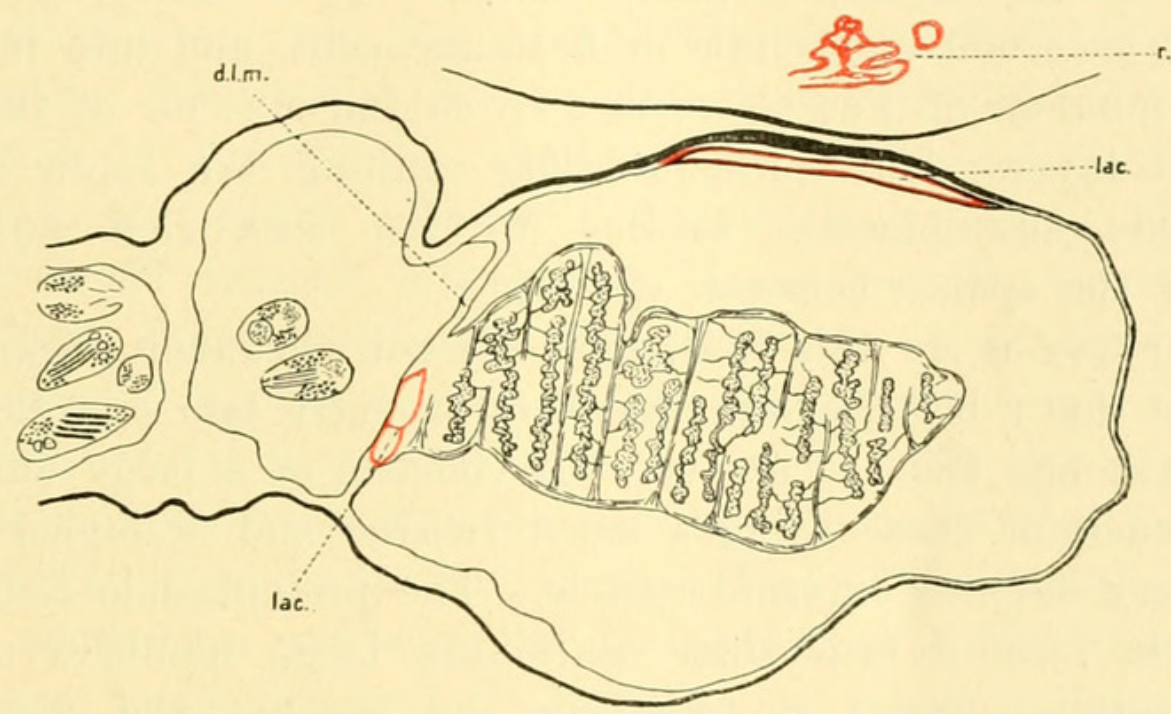

Fig. H.

Fig. E-H illustrate the course of the lacuna entering the body by the peduncle (E), running backwards in the mantle of the upper surface (F) and communicating with the visceral mass by the dorso-lateral mesentery ( $G$ and $H$ ).

lac lacuna, ch.ped chitinous ring of the peduncle, d. $l . m$ dorsolateral mesentery.

The rootsystem and the lacuna in these and other figures is represented in red.

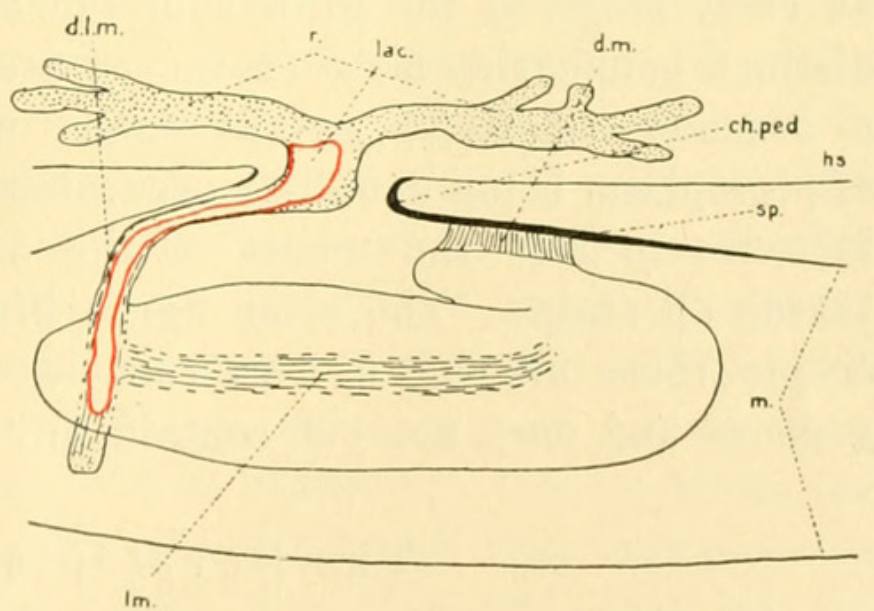

Fig. J. Diagram of the body seen from the right side to show the connection of the rootsystem and the visceral mass.

Abbreviations as in preceding figures. 
visceral mass in the neighbourhood of the longitudinal mesentery (Fig. H) thus forming a dorsolateral mesentery, in which the lacuna runs and conveys nourishment to the visceral mass. This dorsolateral mesentery extends only for a very short space and is succeeded again by a lateroventral mesentery. Posteriorly the visceral mass hangs freely.

The Structure of the Visceral Mass (Pl. 16, Fig. 5-7).

The structure of the visceral mass is extremely simple for it contains only a single organ, the ovary. Externally the visceral mass is enclosed by an irregular ectodermal epithelium of flattened cells, with a very thin cuticle, succeeded by a thin layer of muscle fibres. The interior is principally occupied by a cavity, lined by a definite mesodermal epithelium of flattened cells, and into it project a great number of septa formed from the muscles of the above mentioned layer. The epithelial cells clothing the septa send off innumerable protoplasmic bridles to the ovarian follicles occupying the spaces between the septa.

The ovary is, in this individual a much shrunken organ owing to the fact that a brood of eggs has been recently laid and the organ has not yet had time to recover. It consists of a large number of follicles each of these being a much twisted and crumpled lamella with a very definite external cuticle. The protoplasmic contents of the follicle form a syncytium containing large numbers of small deeply staining nuclei representing the oogonia and also larger nuclei which have aggregated cytoplasm round themselves marking an early stage in the growth of the oocyte. There are not always distinct boundaries between the oocytes but Pl. 16 Fig. 7 represents a common condition, several nuclei with their surrounding masses of protoplasm being definitely separated from each other. With their increase in size the nuclei of the oocytes lose their capacity for taking up stains. The same figure illustrates the fact that in each oocyte there are one or two vacuoles. But the cytoplasm is homogeneous and does not yet contain any yolky constituent.

\section{The Developing Eggs.}

Eggshaped bodies of a much greater size than the young eggs mentioned above, and with a peculiar and uniform structure occur occasionally in the ovary and very commonly in the ventral part 
of the mantle (Pl. 16 Fig. 5). One of these bodies is represented at a higher magnification in Pl. 16 Fig. 8. There is a large central mass of small cells, with small darkly staining nuclei and thin cuticle, strongly similar to the embryonic cells of the Cypris larva. Surrounding this mass is an investment of a yellowish substance, composed of globules, which does not take up borax carmine, and is, in fact, yolk. There is an outer cuticular envelope and in the peripheral yolk there are situated two or three large cells, very vacuolated, with a darkly staining nucleus. Very often too, large vacuoles appear in the yolk, as in the cytoplasm of the oocytes.

When the eggs occur in the ovary they are regularly rounded and the central mass of cells is spherical, but when on the other hand they are found in the mantle-wall they are flattened and distorted in shape and the central cells may tend to disperse.

Among the Cypris larvae in the brood pouch there is a small proportion of bodies of a similar size and appearance, but of a regular ovate shape. These I believe to be eggs which have not developed further into Cypris larvae but for some reason or other have degenerated. In most cases the structure is still recognisable and similar to that of the eggs in the ovary and mantle in that there is a central mass of small cells surrounded by a layer of yolk globules, but the cells are more distributed and stain less definitely than in the other cases (Pl. 16 Fig. 9). But so evident is the connection between the two kinds of bodies that I cannot resist the conclusion that the "developing eggs" in the mantle, do normally dehisce into the mantle cavity.

I have carefully examined the complete series of sections but without finding a trace of a testis or any system of genital ducts. While any conclusions as to the methods of reproduction in this animal must be provisional at present, I suggest that Mycetomorpha is parthenogenetic, that the embryos undergo the first part of their development in the body, larval life being abbreviated by the omission of the Nauplius stage, and that the embryos find their way into the brood pouch without the agency of special ducts. Finally, if my suggestion as to the nature of the problematical bodies in the ovary and mantle is correct, we may suppose that, when the developing embryos attain a certain size, they migrate from the ovary into the mantle, passing between the inner ectodermal lining and the muscular layer. They then break through 
the inner ectodermal epithelium into the mantle cavity and shortly afterwards hatch as Cypris larvae.

But if we do not regard the "developing eggs" as a clue to the reproductive processes of this Rhizocephalan ${ }^{1}$ ) we have to account for the practically simultaneous development of a great number of heavily yolked eggs in the narrow confines of the ovary and for their passage into the mantle cavity without the agency of ducts. It seems to me a vastly more probable explanation that the ova migrate into the body wall thus affording a greater opportunity for the production of a large number of embryos and that they attain the mantle cavity by piercing a thin ectodermal epithelium of the mantle and not by the violent rupture of the walls of the visceral mass. But the ultimate decision of this and other problems connected with the reproduction of Mycetomorpha rests with the observer who is able to obtain further material of this extraordinary creature. The "developing egg" with its central sphere of blastomeres, the peripheral arrangement of the yolk and the three or four vacuolated peripheral cells very possibly represent a hitherto undescribed type of development.

The Glands of the Visceral Mass.

Toward the anterior end of the visceral mass, the ectodermal epithelium becomes modified both dorsally and ventrally over a disclike patch (Fig. K). Under a high power (Pl. 16, Fig. 11) the cells are seen to become tall and columnar and very numerous, each section showing crowds of small deeply staining nuclei not very different from those of the ectoderm elsewhere. Towards their inner boundary the cells contain a granular substance, not stained by borax carmine

1) It was suggested to me that these developing eggs might represent some stage of a Protozoan hyperparasite but of the two gentlemen who were kind enough to examine my sections Mr. K. R. LEWIN of Trinity College, Cambridge could find no definite evidence of their Protozoan nature and Dr. Hinde of Magdalene College was strongly of the opinion that they were not Protozoa.

Mr. Smith tells me that in Sacculina after the eggs are expelled into the mantle cavity a few remain in the ovary and soon degenerate without fertilisation. In Mycetomorpha the bodies appear to be eggs which have reached an advanced state of segmentation and so uniform is the structure that I cannot suppose degeneration to have commenced. 
and largely in the form of globules about the same size as the nuclei. Great masses of the same material have been exuded into the cavity of the ovary, occupying the spaces between the ovarian follicles. Here the substance has a homogeneous granular appearance, the globules having disappeared. There is a general similarity to the yolk which is formed round the periphery of the developing eggs.

It is not certain how far the mesodermal epithelium of the ovarian cavity participates in the production of this secretion. As may be seen in the section drawn here (Pl. 16, Fig. 11) these epithelial cells become larger in the neigbourhood of the glands and contain the gra-

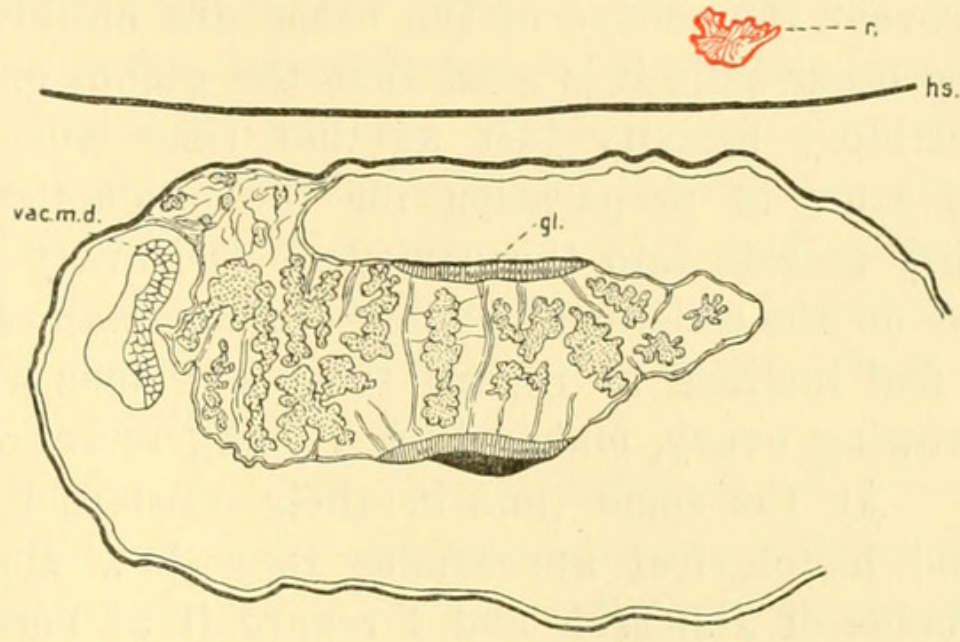

Fig. K. Transverse section through body in the region of the ectodermal glands $(g l)$ of the visceral mass. (Other abbreviations as in preceding figures.) nular substance, but in the middle of the area they appear to be absent. In other sections a proliferation of these mesodermal cells is seen, which may, however, play an important part in secretion. The muscular layer appears to be suppressed throughout the region. The increased activity of the ectodel cells is also shown by the great thickness of the chitinous cuticle $(c h)$ over the glands.

It has been pointed out to me by Mr. Geoffrey Smith that these glands are probably homologous with the colleterial glands of the form described by him as Duplorbis and provisionally assigned to the Rhizocephala. These are disc-shaped organs which are developed from the ectoderm of the visceral mass and consist of columnar epithelial cells. If they represent the colleterial glands of typical Rhizocephala, their structure is much simplified. Nothing is known about the manner in which they function.

The colleterial glands in those forms where their structure and function are best known, Sacculina and Peltogaster, are tubular structures which form part of the female ducts, and they secrete a mucilaginous substance which binds the eggs together when they are forced out of the ovary into the ducts. When these masses of 
eggs finally reach the mantle cavity, the cementing substance solidifies and attaches the eggs to the mantle. ${ }^{1}$ ) In this development of the colleterial glands there is plainly a special adaptation for preventing the emission of embryos during the respiratory movements.

In Mycetomorpha the eggs must be laid in a totally different manner without ducts, and as the mantle aperture is greatly restricted and the size of the eggs probably large, elaborate arrangements to prevent the escape of the brood are unlikely and unnecessary. On the other hand it is seen that the glands of Mycetomorpha are in full secretory activity just at that time when the ova are beginning to grow in preparation for the production of another brood, and they secrete into the cavity of the ovary and not to the exterior (as do the colleterial glands of Sacculina). From these circumstances I feel inclined to regard them as glands which help to nourish the growing ovary, elaborating a yolky secretion.

At the same time in their ectodermal origin, paired character and histological appearance they show similarity to the colleterial glands of Duplorbis and I regard it as possible that they represent also the colleterial glands of the typical Rhizocephala in a greatly modified condition and with a change of function.

The Larvae.

The Cypris larvae of Mycetomorpha are similar to those described so thoroughly by Desage (3) in Sacculina and it is not thought necessary to offer here a detailed account of their structure. In certain features of the histology a slight difference appears. A transverse section of a Cypris larva anterior to the region of the thoracic appendages is shown in Pl. 16 Fig. 10 and represents the various histological elements to be found. There is an epithelium (ep) not always to be easily distinguished from the underlying reticulate tissue (ret) with no cell walls and few nuclei. Dorsally are to be seen the longitudinal muscle $(m u)$ of the limbs cut in section and surrounded by a chitinous sheath. Ventrally, on each side, is a cluster of numerous and very small embryonic cells (using

1) Smith (5), p. 121 , tab. 8 fig. 13.

A further safeguard against the escape of the brood during incubation is the development, in Sacculina, of a special arrangement of hooks, the retinacula, for fixation of the egg-tubes. 
the terminology of Surth = the ovary of Delage). These are the cells which will, judging from the case of Sacculina, give rise to the greater part of the body of the adult animal. In the Cypris they appear to be proliferating, each rounded cytoplasmic mass containing a number of nuclei, as is shown in the figure. More dorsally are situated lateral groups of large cells $(p h)$ which take up little stain and appear to contain a great deal of yolk. They have nuclei small in proportion to the size of the cell and are possibly phagocytic in function. In position and general appearance they correspond to the "refringent vesicles" which DeLage describes as the remains of the food yolk of the Sacculinid Cypris, but their regularity of form and association each with a single nucleus, lead me to assume their cellular nature. In the middle line however is to be seen a nonstaining area of a granular substance which is certainly the residue of the yolk of the egg.

It must be mentioned here that though hundreds of Cypris larvae were included in the series of transverse sections, microscopic examination of these failed to show any with spermatozoa, developing or mature. Nor were any bodies found elsewhere which could be interpreted as larval males and in the face of this negative evidence we must conclude for the present that the animal is parthenogenetic.

\section{Relationships of Mycetomorpha.}

No doubt can be entertained as to the inclusion of this form among the Rhizocephala, but it does not come near any previously described genus. Asymmetry is a feature of the group but it reaches its climax in Mycetomorpha. In reviewing the genera of the Rhizocephala, with their varying degrees of asymmetry, Sмıтн (5, p. 12-18) has found it possible to derive nearly all of them from the almost symmetrical form Peltogaster and a profitable comparison with that genus may be made in this case too. The differences to be seen between Fig. $\mathrm{L}$ and $\mathrm{M}$ are mostly to be explained by supposing two chief movements of displacement. (1) a revolution through $90^{\circ}$ of the visceral mass and mesentery to the right side (with reference to the peduncle). (2) a subsequent curvature of the visceral mass which causes the originally anterior mantle aperture to be directed inwards, and is responsible for the formation of the bay. The expansion of the mantle cavity is probably at later change. A third element of asymmetry is introduced by the oblique setting of the 
peduncle and the posterior connection of the lacuna with the visceral mass (its course being also complicated by the lateral revolution of the visceral mass).

The glands of the visceral mass, it may be noticed in Fig. L, occupy a position which justifies their identification as colleterial glands. It is unfortunate that the presence of a ganglion has not been detected in Mycetomorpha.

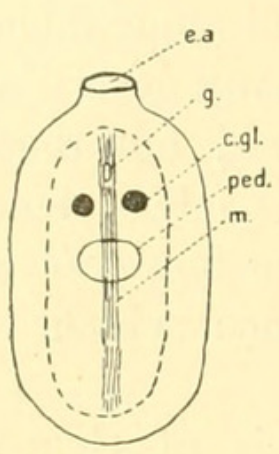

Fig. L.

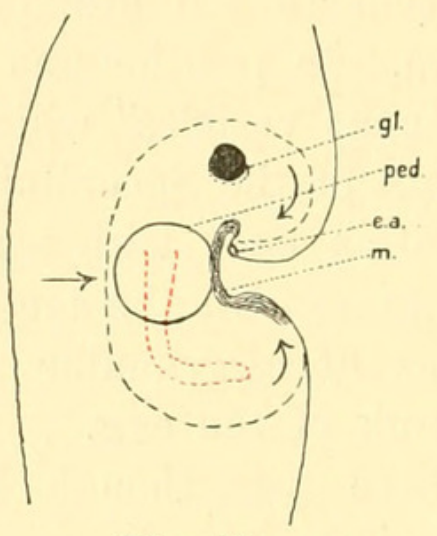

Fig. M.
Fig. L. Diagram of Peltogaster seen from the dorsal surface.

Fig. M. Diagram of Mycetomorpha seen from the dorsal surface. Course of the lacuna of the root-system indicated in red.

c. $g l$ colleterial gland. $g l$ glands of visceral mass. $g$ ganglion.

Other abbreviations as in other figures.

The arrows in Fig. M represent the directions of torsion.

Sylon is the only other member of the order which is parasitic on shrimps but in spite of this community of habitat there is little resemblance between the two forms for Sylon is the most symmetrical Rhizocephalan and is distinguished from its relations by the presence of two mantle openings. The one character they may have in common is reproduction by parthenogenesis.

Two little known genera of Rhizocephala agree with Mycetomorpha in the presence of Cypris larvae in the mantle cavity. These are Thompsonia (Kossmann 4) on Melia and Sesarmaxenos recently described by Annandale (1) from freshwater crabs. But though the three forms possess a development accelerated by the suppression of the Nauplius stage there are no other features of structure or biology which indicate close relationship.

The homology of the glands of Duplorbis and Mycetomorpha has already been discussed. The thinness of the mantle and the poverty of connective tissue in the visceral mass are other points in common. Mr. Sмiтн suggested to me that the lacuna described in Mycetomorpha resembles the mesenteric canal of Duplorbis. But the lacuna does not open into the mantle cavity and is not lined by an epithelium or chitinous layer but is connected with a rootsystem. Mycetomorpha then can scarcely be regarded as helping to bridge the gap between Duplorbis and the Rhizocephala with a typical rootsystem. 


\section{Diagnosis of Genus Mycetomorpha.}

Parasitic on ventral surface of abdomen of a shrimp Crangon communis. Solitary.

External body flattened and mushroom shaped, length greater than breadth, colour pale yellow, borders fringed with numerous short lobes.

Rootsystem not widely distributed, situated under nerve cord of host, colourless.

M antle smooth, very thin, with feeble musculature.

Mantle cavity enormously enlarged and produced into the lateral lobes which together with the main cavity are filled with Cypris larvae.

M antle opening small, situated at apex of a tubular structure with narrow lumen, the mantle duct on left side of visceral mass.

Visceral mass very small in relation to the total size of body, displaced to the apparent left side of the animal, forming a semicircular curve.

Peduncle short, runs obliquely into body of host pointing. anteriorly: chitin of the ring continued anteriorly as a median spike.

Lacuna of rootsystem communicates with visceral mass far posteriorly by dorsolateral mesentery. Main mesenteric connection runs along left side.

Ganglion not known.

Testes absent.

Colleteric glands possibly represented by paired discs on surface of visceral mass.

Female ducts absent.

Larval males absent.

M. vancouverensis. Characters of species those of genus.

A note on the Sexual Condition in Sylon.

Sylon has already been recorded from Puget Sound by W. T. CaLMan (2) who described S. hippolytes as occurring on Hippolyte brevirostris, Pandalus danae and Sclerocrangon munitus. A large number of individuals were collected in 1909 by Miss Kathleen Haddon and in 1911 by myself while working at the Marine Biological Station of the University of Washington, situated at Friday Harbour in the San Juan Archipelago. In his monograph on the Rhizocephala Mr. Sмiтt describes Sylon as structurally a female and not a herm- 
aphrodite reaching this conclusion after examining sections of four individuals which he was able to obtain. I submitted my collection of Sylon to Mr. Sмiтt and he asks me to state, in support of his former assertion, that four more individuals of varying sizes were sectioned and in none of them could a testis be found.

It may then be stated that in three genera of the Rhizocephala Sylon, Sesarmoxenos and Mycetomorpha careful examination has not revealed the presence of the male organ or the occurrence of larval males. The presumption, then, is that these forms reproduce parthenogenetically, but it is of great importance that an investigation of their reproduction should be undertaken in some locality like Puget Sound, where one of the forms, at least, can be obtained in quantity.

\section{Bibliography.}

1. Annandale, in: Records Ind. Mus. Calcutta, Vol. 6 (1911), p. 1-4.

2. Calman, On a collection of Crustacea from Puget Sound, in: Ann. New York Acad. Sc., Vol. 11, 1898, p. 259.

3. Delage, Evolution de la Sacculine, in: Arch. Zool. expér. (2), Vol. 1, 1884, p. 417-738, tab. 22-30.

4. Kossmann, Beiträge zur Anatomie schmarotzender Rankenfüssler, in: Arb. zool.-zoot. Inst. Würzburg, Vol. 1, 1874, p. 97.

5. Sмгтн, G. W., Rhizocephala, in: Fauna Flora Golf Neapel, Vol. 19, p. $1-123$, tab. $1-8$. 


\title{
Explanation of the Figures.
}

\author{
$b r$ protoplasmic bridles connecting $n . c$ nerve cord of host \\ ovarian follicles with septa o. $f$ ovarian follicle \\ ch chitinous cuticle of ectoderm ooc oocytes \\ ch.ped chitinous ring surrounding oog oogonia \\ peduncle \\ ect ectoderm of mantle \\ ect ${ }^{t}$ ectoderm of visceral mass \\ emb developing eggs \\ emb. $c$ embryonic cells of Cypris larva \\ ep surface epithelium of Cypris larva \\ l. $m$ longitudinal musculature of the \\ host, Crangon \\ m. $c$ mantle cavity \\ $m$. $d$ mantle duct \\ ph phagocytic cells of Cypris larva \\ ret reticular tissue of Cypris larva \\ $r$ rootsystem \\ $b$ granular substance secreted by \\ the glands of the visceral mass \\ sep septa of visceral mass \\ $s p$ chitinous spike given off from \\ peduncular ring \\ rac vacuole \\ $y$ residual yolk in Cypris larva
} $m u$ muscles

\section{Plate 15 .}

Fig. 1. Ventral view of the shrimp Crangon communis with its parasite Mycetomorpha vancouverensis. $3: 1$.

Fig. 2. Lateral view of the same: the right pleurae and appendages of the first two abdominal segments have been removed to show the attachment of the parasite more plainly. $3: 1$.

$$
\text { Plate } 16 .
$$

The figures in this plate refer entirely to Mycetomorpha.

Fig. 3. Upper surface of Mycetomorpha detached from its host: the visceral mass and mantle duct are shown as seen through the mantle when the larvae have been removed from the mantle cavity. $5: 1$. 
Fig. 4. Portion of rootsystem, running underneath the ventral nerve cord of Crangon, stained and mounted whole.

Fig. 5. Transverse section about the middle of the body showing developing eggs in the visceral mass and the mantle.

Fig. 6. Transverse section through portion of visceral mass showing two muscular septa and intervening ovarian follicle. 490:1.

Fig. 7. Young oocytes in an ovarian follicle. 520:1.

Fig. 8. Developing egg as seen in transverse section of the visceral mass. section.

Fig. 9. Degenerating egg from the mantle cavity cut in transverse

Fig. 10. Cypris larva in transverse section.

Fig. 11. Transverse section of the visceral mass showing the ectodermal glands. $310: 1$. 


\section{$2 \mathrm{BHL}$ Biodiversity Heritage Library}

1912. "Mycetomorpha, a new Rhizocephalan (with a note on the sexual condition of Sylon)." Zoologische Jahrbücher 33, 575-594.

https://doi.org/10.5962/bhl.part.17421.

View This Item Online: https://www.biodiversitylibrary.org/item/38129

DOI: https://doi.org/10.5962/bhl.part.17421

Permalink: https://www.biodiversitylibrary.org/partpdf/17421

\section{Holding Institution}

MBLWHOI Library

Sponsored by

MBLWHOI Library

\section{Copyright \& Reuse}

Copyright Status: NOT_IN_COPYRIGHT

This document was created from content at the Biodiversity Heritage Library, the world's largest open access digital library for biodiversity literature and archives. Visit BHL at https://www.biodiversitylibrary.org. 